\title{
A AVALIAÇÃO NA EDUCAÇÃO PROFISSIONAL DE JOVENS E ADULTOS
}

\author{
THE EVALUATION IN YOUTH AND ADULT PROFESSIONAL EDUCATION
}

\section{EVALUACIÓN EN LA EDUCACIÓN PROFESIONAL DE JÓVENES Y ADULTOS}

\author{
Kênya Maria Vieira Lopes* (D) 0
}

Nádia Maria Pereira de Souza** (D) 0

\section{RESUMO}

Apresenta-se neste artigo alguns dos resultados da dissertação defendida em março do ano de 2011 na Universidade Federal Rural do Rio de Janeiro por meio do Programa de Pós-Graduação em Educação Agrícola, em Seropédica-RJ. O trabalho teve como título A avaliação do Processo/Ensino Aprendizagem no PROEJA do Instituto Federal do Tocantins Campus Araguatins. Buscou-se analisar a prática avaliativa dos professores do curso PROEJA - Agroindústria no Campus Araguatins, do Instituto Federal do Tocantins. Logo, entende-se que à medida que há mudança nos programas educacionais, deve-se discutir sobre a avaliação. Discutir tal abordagem do ensino e aprendizagem é repensar a educação. A pesquisa teve abordagem qualitativa e envolveu a participação de 15 professores colaboradores que ministraram aula no ano de 2009 no curso Técnico em Agroindústria do Campus Araguatins, do IFTO. Utilizou-se um questionário semiestruturado envolvendo questões desde a concepção de avaliação dos docentes à definição de preferência de instrumentos avaliativos usados pelos mesmos em sala de aula. O presente estudo, apresentará os resultados referentes aos instrumentos de avaliação escolhidos pelos docentes, os quais têm como preferência a prova escrita, e a análise dos professores sobre a estrutura de avaliação proposta pela instituição, que entre outras regras, utiliza-se da Semana de prova. Se avaliar o aluno tido como regular que estuda em período diurno e não trabalha apresenta suas dificuldades, como avaliar o jovem ou adulto, em sua maioria trabalhador, em um curso de educação profissionalizante?

Palavras-chave: Avaliação. Ensino Profissional. Educação. Jovens e Adultos.

\begin{abstract}
This article presents some of the results of the dissertation defended in March 2011 at the Federal Rural University of Rio de Janeiro through the Graduate Program in Agricultural Education, in SeropédicaRJ. The work was entitled Assessment of the Learning Process/Teaching in PROEJA of the Federal Institute of Tocantins Campus Araguatins. It was sought to analyze the evaluation practice of the professors of the PROEJA - Agroindustry course on Campus Araguatins, of the Federal Institute of Tocantins. Therefore, it is understood that as there are changes in educational programs, there must be discussion about the evaluation. To discuss about teaching-learning evaluation is to rethink education. The research had a qualitative approach and involved the participation of 15 collaborating professors who taught, in 2009, the Technical course in Agroindustry at Campus Araguatins, IFTO. A semistructured questionnaire was used, involving questions from the conception of teacher evaluation to the definition of preference for the evaluation instruments used by them in the classroom. For this work, the

\footnotetext{
* Doutoranda em Educação em Ciências e Matemática do PPGECEM/REAMEC-UFMT, Mestre em Educação Agrícola pela UFRRJ. Professora do Instituto Federal de Educação do Tocantins (IFTO), Campus Porto Nacional. Av. Tocantínea, Porto Nacional, TO, Brasil, CEP: 77.500-000. E-mail: kenya@ifto.edu.br

** Doutora em Ciências Sociais: Desenvolvimento, Agricultura e Sociedade pela Universidade Federal Rural do Rio de Janeiro. Professora Titular da UFRRJ, PPGEA - IA. Antiga Estrada Rio São Paulo Km 47. Seropédica, RJ, Brasil, CEP: 23851970. E-mail: nmpsouza@uol.com.br
} 
results will be highlighted referring to the assessment instruments chosen by the teachers, which prefer the written test, and the analysis of the teachers on the evaluation structure proposed by the institution, which, among other rules, uses the Evaluation Week. If evaluating the student considered to be regular who studies during the day and does not work presents its difficulties, how to evaluate the Youth or Adult, mostly workers, in a vocational education course?

Keywords: Evaluation. Professional Education. Education. Youth and Adults.

\section{RESUMEN}

Este artículo presenta algunos de los resultados de la disertación defendida en marzo de 2011 en la Universidad Federal Rural de Río de Janeiro a través del Programa de Posgrado en Educación Agrícola, en Seropédica-RJ. El trabajo tuvo el título Evaluación del Proceso de Aprendizaje / Docencia en el PROEJA del Instituto Federal de Tocantins. Se buscó analizar la práctica evaluativa de los profesores del curso PROEJA - Agroindustria en el Campus Araguatins, del Instituto Federal de Tocantins. Por tanto, se entiende que ante un cambio en los programas educativos, se debe discutir la evaluación. Discutir la evaluación como un enfoque de enseñanza y aprendizaje es repensar la educación. La investigación se presenta como un personaje con enfoque cualitativo y contó con la participación de 15 profesores colaboradores que impartieron, en 2009, en el Curso Técnico en Agroindustria en IFTO Campus Araguatins, en IFTO. Se utilizó un cuestionario semiestructurado, que involucró preguntas desde la concepción de la evaluación docente hasta la definición de preferencia por los instrumentos de evaluación que utilizan en el aula. Para el presente estudio de trabajo, se destacarán los resultados referidos a los instrumentos de evaluación elegidos por los profesores, quienes tienen como preferencia la prueba escrita, y el análisis de los profesores sobre la estructura de evaluación propuesta por la institución, que, entre otros reglas, utiliza la Semana de prueba. Si evaluar al estudiante considerado regular que estudia durante la jornada y no trabaja presenta sus dificultades, ¿cómo evaluar al joven o adulto, mayoritariamente trabajadores, en un curso de formación profesional?

Palabras clave: Evaluación. Educación profesional. Educación. Jóvenes y adultos.

\section{INTRODUÇÃO}

Os resultados da pesquisa, que ora apresentados, fazem parte da dissertação de mestrado intitulada A avaliação do Processo/Ensino Aprendizagem no PROEJA do Instituto Federal do Tocantins Campus Araguatins e defendida em 14 de março de 2011 no Programa de PósGraduação em Educação Agrícola (PPGEA) na UFRRJ, teve como objetivo "analisar as práticas pedagógicas da avaliação do processo ensino - aprendizagem no curso Técnico PROEJA em Agroindústria do IFTO Campus Araguatins”. (LOPES, 2011, p. 42). A pesquisa foi desenvolvida entre 2008-2009.

Para iniciar a discussão, ressalta-se que a Educação de Jovens e Adultos (EJA) é explicitada na Lei de Diretrizes e Bases da Educação Nacional (LDB), nos artigos 37 e 38 conforme descrito a seguir: 
constituirá instrumento para a educação e a aprendizagem ao longo da vida. ("Caput" do artigo com redação dada pela Lei n ${ }^{\circ} 13.632$, de 6/3/2018)

$\S 1^{\circ}$ Os sistemas de ensino assegurarão gratuitamente aos jovens e aos adultos, que não puderam efetuar os estudos na idade regular, oportunidades educacionais apropriadas, consideradas as características do alunado, seus interesses, condições de vida e de trabalho mediante cursos e exames.

$\S 2^{\circ} \mathrm{O}$ Poder Público viabilizará e estimulará o acesso e a permanência do trabalhador na escola, mediante ações integradas e complementares entre si.

$\S 3^{\circ}$ A educação de jovens e adultos deverá articular-se, preferencialmente, com a educação profissional, na forma do regulamento. (Parágrafo acrescido pela Lei $\mathrm{n}^{\mathrm{o}}$ 11.741 , de $16 / 7 / 2008)$

Art. 38. Os sistemas de ensino manterão cursos e exames supletivos, que compreenderão a base nacional comum do currículo, habilitando ao prosseguimento de estudos em caráter regular.

$\S 1^{\circ}$ Os exames a que se refere este artigo realizar-se-ão:

I - no nível de conclusão do ensino fundamental, para os maiores de quinze anos;

II - no nível de conclusão do ensino médio, para os maiores de dezoito anos.

$\S 2^{\circ}$ Os conhecimentos e habilidades adquiridos pelos educandos por meios informais serão aferidos e reconhecidos mediante exames. (BRASIL, 1996)

Com a atualização do artigo 37 da LDB no ano de 2018, tem-se o entendimento da EJA como uma modalidade de ensino que visa atender jovens e adultos, e que, em simultâneo, consiste na garantia da aprendizagem em todo o percurso de vida ao estudante que não teve oportunidade de concluir os estudos na idade adequada. Cabe destacar, nesse mesmo artigo, a proposição para que a modalide seja ofertada, de forma preferencial, com a Educação Profissional.

Considera-se que a implementação do Programa Nacional de Integração da Educação Profissional com a Educação Básica na Modalidade de Jovens e Adultos- PROEJA, ocorrida por meio do Decreto 5.478 de 24 de junho de 2005 (BRASIL, 2005a), e suas alterações, foi uma ação (entre tantas outras existentes até então) para viabilizar a articulação entre EJA e ensino profissionalizante, tal como instruído pela LDB.

O Campus Araguatins, do Instituto Federal do Tocantins (o lócus da pesquisa do mestrado) localizado no extremo-norte do Estado, que fica a cerca de $600 \mathrm{~km}$ da capital do Estado - Palmas, foi uma das primeiras instituições da região a oferecer um curso pelo PROEJA. No ano de 2006, iniciou-se o curso de Técnico em Agroindústria, e em 2007, o curso Técnico em Informática. O documento norteador do programa, Brasil (2005b), enfatizava a importância de as formações ofertadas nessa modalidade (que visa integrar a educação básica com um curso profissionalizante) garantirem uma proposta metodológica de ensino com os mesmos padrões de qualidade dos demais, com articulação entre os conhecimentos prévios dos estudantes, uso de didáticas inovadoras com vista às novas aprendizagens, além disso, deixava evidente a ideia de avaliação que não visasse apenas classificar o aluno. Foi com base em tal contexto que se 
propôs discutir a avaliação do ensino-aprendizagem na modalidade de educação profissionalizante de jovens e adultos.

A pesquisa surgiu mediante inquietações advindas por meio do trabalho da autora que atuava como coordenadora pedagógica nos cursos PROEJA da instituição em questão. Naquele ano, 2008, o Campus ofertava duas turmas do Curso Técnico em Informática e uma de Agroindústria. Por serem cursos novos na instituição e parte dos professores atuarem, até a implementação do programa, apenas com as turmas regulares ofertadas no período diurno, suscitaram-se os seguintes questionamentos: como o professor avalia o jovem e adulto do PROEJA? Quais os instrumentos de avaliação utilizam e por quais tem preferência?

A pesquisa teve abordagem qualitativa e envolveu a participação de 15 professores colaboradores que ministraram aula em 2009, no curso Técnico em Agroindústria do Campus Araguatins, do IFTO. Utilizou-se um questionário semiestruturado envolvendo questões desde a concepção de avaliação dos docentes à definição de preferência de instrumentos avaliativos usados pelos mesmos em sala de aula.

Apresenta-se neste artigo alguns dos resultados referentes aos instrumentos de avaliação escolhidos pelos professores, os quais têm como preferência a prova escrita, e a análise dos professores sobre a estrutura de avaliação proposta pela instituição, que entre outras regras, utiliza-se da Semana de provas.

Se avaliar o aluno tido como regular que estuda em período diurno e não trabalha apresenta suas dificuldades, como avaliar o jovem ou adulto, em sua maioria trabalhador, em um curso de educação profissionalizante?

\section{A EDUCAÇÃO DE JOVENS E ADULTOS E A EDUCAÇÃO PROFISSIONAL}

Na literatura sobre Educação de Jovens e Adultos, encontram-se autores que tratam o termo abordando a história da EJA por meio da implantação de programas de alfabetização de adultos. A utilização da expressão nos remete a lembrar de autores tais como Gadotti (2008) que, ao conceituar educação de jovens e adultos, alerta para que não se confunda com uma educação popular. Logo, entende-se que esse processo de ensino é sistemático, formal e escolar o que a torna diferente da educação popular.

Considerando as proposições dos artigos 37 e 38 da LDB (BRASIL, 1996), descritos na introdução deste trabalho, pode-se definir educação de jovens e adultos como um processo formativo destinado a estudantes que não tiveram oportunidades de estudos em idade regular. 
Trata-se de uma educação básica que apresenta como diferencial um público com característica peculiar: pode ter outra profissão além de estudante.

Também há a abordagem sobre este assunto no processo do ensino profissionalizante. A história da EJA confunde-se com a da Educação Profissional no sentido de que, tanto uma quanto a outra, em momentos marcos, consideram a aprendizagem obtida de maneira informal na experiência de vida das atividades cotidianas. A tentativa de universalização da Educação Básica é exemplificada na integração da educação de jovens e adultos com a profissional (LOPES, 2011).

O ensino integra-se no tempo-espaço, possui um objetivo social, econômico e político e com base neles pode sofrer alterações, pois é influenciado pelo contexto histórico-social. O que se espera da escola, do professor, do aluno, das políticas públicas e da sociedade, em uma determinada época, pode transformar a história da educação.

A história da Educação Profissional no Brasil aponta diferentes olhares e funções quanto ao seu foco de atuação, à medida que foi passando de educação informal (aquela que visa a aprendizagem sobre determinada atividade profissional, caça, pesca, repassada de pais para filhos ou de mestres para aprendizes) para a formal com fomento por meio das políticas públicas do Estado. Tal ação permite destacar que do período colonial aos dias atuais, o ensino caracterizado como de restrito acesso, em que apenas uma classe poderia obtê-la, tem buscado como caracterização a disposição de um notável crescimento e facilidade de acesso à população em carência dessa modalidade de ensino (LOPES, 2011).

Frigotto, Ciavatta e Ramos (2005), Kuenzer (2007) e Manfredi (2002) foram alguns dos autores citados no trabalho de Lopes (2011) que facilitou a revisão histórica da Educação Profissional. Entre estas literaturas encontram-se registros de ações/programas adotadas no Brasil (ao longo dos últimos dois séculos) com relação ao trabalho, à prática educativa e ao processo de aprendizagem de alguma profissão. Tais leituras possibilitaram também concluirse que a proposta de unir educação profissional com a básica é anterior a implementação do PROEJA, por exemplo. Todavia, é necessário assinalar que para alguns desses teóricos essa integração (educação profissional e básica) é ausente na prática.

\section{O PROCESSO ENSINO - APRENDIZAGEM E A AVALIAÇÃO}

O que é ensino? O que é aprendizagem? O que é avaliação? Considera-se que chegar a tais respostas não é uma tarefa fácil (tampouco objetivo deste). Posto isso, mesmo que tais 
definições existam, elas podem não ser concluídas.

Poderia o processo de ensino ter surgido, depois de Cristo, nos momentos que ele buscava instruir as pessoas pelas pregações de evangelização, explicando com exemplos práticos e de vida, esclarecendo a lição que pretendia que todos soubessem? Seria a aprendizagem a compreensão do assunto que Cristo falava? Aprendia aquele que conseguia colocar em ação a instrução do mestre? E antes de Cristo como era o ensino?

A discussão sobre a temática ensino-aprendizagem pode ser ampla e densa por se tratar de um processo que transcende o espaço escolar. Todavia, é com foco neste ambiente que se pretende discutir.

Refletir sobre o ensino-aprendizagem é pensar no aluno, no professor, na relação entre eles, no ambiente onde tal interação acontece e nas condições e fatores que podem afetar diretamente esse processo. Será o professor aquele que ensina? Porventura é o aluno aquele que aprende? Em uma resposta afirmativa a ambas as questões acrescentar-se-ia uma relação dialógica entre discente e docente na visão já defendida por alguns educadores, de que ao ensinar o professor aprende e ao compreender o aluno também ensina. Seja por isso o ensinoaprendizagem consistir em um transcurso.

Sobre o processo ensino-aprendizagem assim discorre Lopes (2011, p. 22): "pode ser analisado pela caracterização do papel da escola, pela forma como os conteúdos e métodos de ensino são trabalhados, pela definição da relação professor-aluno, como a aprendizagem é tratada".

Diretamente relacionada a tal contexto está a avaliação. Esta que também pode ser discutida além do espaço escolar, considerando que avaliar é uma ação que faz parte do cotidiano de cada indivíduo, inerente à atividade humana. Logo, é da natureza humana a necessidade de emitir juízos sobre o que o cerca.

Seria a avaliação um julgamento de valor?

"O termo avaliar provém etimologicamente de dois outros termos latinos: prefixo a e verbo valere, que significa, 'dar valor a'; em síntese, atribuir qualidade a”, assim afirmou Luckesi (2002 p.79).

A literatura sobre avaliação é vasta, inclusive as que tratam sobre o rendimento discente. De forma breve pode-se elencar alguns conceitos tais como: "tratar a avaliação da aprendizagem como 'medida', ‘julgamento de valores', 'classificação', 'diagnóstica', 'formativa', 'somativa', entre outros”'. (LOPES, 2011, p. 23).

Sousa (2005) acredita que a avaliação é um julgamento de valor e tem por finalidade 
determinar se os objetivos educacionais estão sendo alcançados. Ela deve servir para organizar e interpretar dados, permitir constantes reflexões, aferir e comparar resultados e modificar a conduta dos estudantes. A avaliação contribui para a elaboração do currículo, consistindo em um sistema de controle da qualidade do processo ensino-aprendizagem.

Essa mesma autora aborda que nos primeiros anos da década de 60, quando a temática avaliação educacional começou a ser discutida no Brasil, o ato de avaliar possuía caráter estritamente técnico, procedimental. Situação essa que é justificável ao se considerar o fato de a avaliação do ensino-aprendizagem ter tido como base epistemológica a teoria geral da administração.

Sobre a base epistemológica da avaliação do ensino-aprendizagem, assim afirma Lopes (2011):

Pressupõe-se que essas origens conceituais sobre avaliação advindas ao Brasil e até mesmo a prática constante da educação tradicional, vinda com uma nova roupagem na pedagogia tecnicista na época da ditadura, contribuiu no encadeamento do uso da avaliação como controle, racionalização do sistema de ensino e produtividade. (p.27)

Entre os autores que discutem sobre avaliação, tem-se uma aproximação com os conceitos apresentados por Vasconcellos (2006). O autor, ao provocar reflexões sobre essa temática como um processo dialético do ensino-aprendizagem, aborda que não se pode avaliar com o objetivo de controlar e enfatiza a importância de a avaliação ser utilizada como recurso metodológico de orientação pedagógica ao professor ao ponto de se tornar um instrumento e que o aluno possa aprimorar a aprendizagem.

Darsie (2010) ao propor discussões sobre as concepções e práticas de avaliação na Educação Matemática, discorre sobre alguns pareceres permanentes na prática avaliativa dos docentes, entre elas, a avaliação tradicional enraizada pela concepção de análise classificatória. Cabe ressaltar que a avaliação tradicional tende a colocar o professor como detentor do conhecimento.

Nesse sentido, entende-se que uma avaliação que se pauta na visão tradicional de ensino apresenta como objetivo: definir o que aluno aprendeu ou não aprendeu sem considerar o erro como parte do processo de aprendizagem. Concepção essa que, segundo Hoffmann (2004), é predominante, na prática escolar. Para ela, a função classificatória da avaliação centra-se na atribuição do valor ao aluno: aprovado ou reprovado, ao final da série ou grau de ensino. 
Destaca-se que essa mesma autora é uma das referências na discussão da temática da utilização do erro do educando (durante a avaliação) como integrante do ensino-aprendizagem.

Entende-se que o erro pode ser o ponto de partida para que se modifique a metodologia de ensino e as estratégias didáticas, e, dependendo da forma como é tratado pelo professor e pelo aluno, ele pode consistir em estímulo para que o aluno busque superar as dificuldades da aprendizagem e o professor a repensar a sua prática.

Lopes (2011) enfatiza em seu trabalho quatro concepções de avaliação que considera como ideais a serem aplicadas na prática pedagógica. Segue um quadro síntese de tais concepções, para melhor compreensão do leitor.

\begin{tabular}{|c|l|c|}
\hline Concepção de Avaliação & \multicolumn{1}{c|}{ Definição } & Autor que a defende \\
\hline \multirow{5}{*}{ M) Construtivista } & $\begin{array}{l}\text { É um processo que permite a professores e alunos a } \\
\text { utilização dos resultados obtidos com a avaliação como } \\
\text { base para consolidação de novos conhecimentos. Nela, } \\
\text { o erro é entendido como um instrumento de análise para } \\
\text { se rever as formas de avaliar. }\end{array}$ & Hoffmann (2005, 2004) \\
\hline b) & $\begin{array}{l}\text { É uma etapa da construção do conhecimento. A } \\
\text { avaliação deve ser um trabalho de intersecção, } \\
\text { intermediação e intervenção entre o que o estudante } \\
\text { aprendeu e o que ele pode vir a aprender. Trata o erro } \\
\text { como construtivo. }\end{array}$ & Hoffmann (2004) \\
\hline c) Emancipatória & $\begin{array}{l}\text { É um momento de reflexão, onde se procura analisar } \\
\text { criticamente os resultados obtidos, partindo-se dessa } \\
\text { análise para modificar a realidade avaliada. }\end{array}$ & Saul (1998) \\
\hline d) Dialética- & $\begin{array}{l}\text { É dialética. Entende a avaliação como um potencial para } \\
\text { transformar a realidade e como tal deve postar } \\
\text { constantemente em análise e debate. Deve-se superar os } \\
\text { absurdos lógicos pelos quais se pautam o ato de avaliar } \\
\text { e ser avaliado. }\end{array}$ & Vasconcellos (2006) \\
\hline
\end{tabular}

Quadro 1 - Concepções de avaliação necessárias à Prática Educativa

Fonte: Adaptado de Lopes (2011)

Embora se tenha apresentado tais concepções de forma separada, compreende-se que esse conjunto de conceitos deve nortear o exercício pedagógico. De forma geral, consta no quadro supracitado a concepção de avaliação que se espera visualizar na educação: análise entendida como recurso base da prática pedagógica e não como instrumento de validação do erro. Com base em tais reflexões que se propôs a análise da ação avaliativa dos docentes no PROEJA do Campus Araguatins, do IFTO.

\section{A PRÁtica AVAliativa dOS DOCENTES NO PROEJA DO CAMPUS ARAGUATINS, DO IFTO}

O objetivo da pesquisa da qual se originou esse artigo, consistiu em analisar as práticas 
pedagógicas da avaliação do processo ensino-aprendizagem no curso Técnico PROEJA em Agroindústria do Campus Araguatins, do IFTO. O estudo foi de abordagem qualitativa e ocorreu entre os anos de 2008-2009. Os colaboradores foram os docentes da turma Técnico em Agroindústria do PROEJA. Utilizou-se um questionário como instrumento de coleta de dados. A instituição em estudo contava com 15 (quinze) professores ministrando aulas na referida turma.

No instrumento utilizado para coleta de dados da pesquisa do mestrado, constavam cerca de 30 questões distribuídas em quatro eixos assim nomeados: 'dados cadastrais', 'dados referentes à atividade profissional'; 'questões sobre avaliação' e 'trabalho com o PROEJA'. No primeiro eixo constavam duas questões referentes ao grau de titulação do professor quando ele entrou na instituição e a titulação tida no momento da resposta do instrumento. No segundo, o questionamento ao professor deu-se sobre o sobre seu tempo de atuação como docente, sua situação de carga horária-aula, bem como, sobre sua experiência com a docência na educação de jovens e adultos. O terceiro e quarto eixos, embora com nomenclaturas diferentes, concentraram-se em questões relacionadas à teoria e à prática de avaliação docente até as impressões que o professor tinha sobre como desenvolvia tal ação avaliativa no PROEJA. Tais respostas foram discutidas em Lopes (2011).

Delimitar-se-á, neste artigo, na análise das questões referentes ao conceito que o docente apresenta sobre o termo avaliar; aos procedimentos avaliativos utilizados pelos professores em sua prática pedagógica e a opinião dos colaboradores sobre a regulamentação existente na instituição para a avaliação discente.

Dos docentes colaboradores da pesquisa, 9 (nove) possuíam o grau de especialistas. Cinco deles eram apenas graduados e 1 (um), mestre. Do total geral, 8 (oito) tinham contrato temporário com a instituição e 7 (sete) eram concursados efetivos, sendo que parte desses professores de contrato temporário tinha mais de 24 (vinte e quatro) horas aulas semanais por também atuarem em outra instituição de ensino na cidade. A maioria deles, 10 (dez), contava com a experiência com a Educação de Jovens e Adultos antes de ministrarem aula no PROEJA. Talvez por isso afirmaram que não havia dificuldade em trabalhar com esse público.

Cabe ressaltar que em 2009 a instituição começava a estruturar-se como Instituto Federal de Educação, ao considerar que antes (até 29 de dezembro de 2008) era Escola Agrotécnica Federal de Araguatins.

Considera-se que tais dados, como o de titulação dos docentes, hoje seriam diferentes. Nesta primeira década de IFTO, foram implementados programas de capacitação para os 
servidores para a melhoria da profissionalização docente, colaborando assim com o tema em discussão: a avaliação. Há autores, como Vasconcelos (2006), que afirmam que a mudança da postura do educador diante da avaliação da aprendizagem também depende dos investimentos na formação do professor.

Sobre o conceito atribuído ao termo avaliar, assim afirma alguns dos professores colaboradores: "Verificar o nível de aprendizagem em determinado momento a fim de melhorar uma situação futura. (Colaborador 10)"; "Conhecer o grau de aprendizagem de determinado assunto e tentar observar algumas falhas. (Colaborador 07)”.

Entende-se que os docentes, de forma geral, definiram avaliar como um meio para verificar as habilidades e competências adquiridas pelos alunos, "os sucessos e as dificuldades deste, como para verificar se os objetivos de aprendizagem foram atingidos utilizando desses resultados para aprimorar as práticas pedagógicas” (LOPES, 2011, p.63).

Buscando categorizar as demais respostas dos professores sobre a questão 'Avaliar é?', observa-se que as mesmas se centram na ideia dessa classificação como uma ação que verifica a aprendizagem do aluno, inclusive para identificar as falhas do professor, como destacado pela resposta, supracitada, do Colaborador 7. Observa-se que as conclusões dos professores ao termo 'avaliar' se aproximam do mapa conceitual apresentado no Quadro 1.

Entre as questões introdutórias sobre avaliação (expostas no eixo três do questionário) constava um enunciado que deixava em aberto o espaço para o professor tecer sua opinião sobre a prática avaliativa que eles utilizavam, ter alguma relação (ou não) com a formação acadêmica alcançada. A questão posta foi: "Em sua opinião, o que o levou a adotar os métodos avaliativos em aula está relacionado à sua formação?” (LOPES, 2011, p. 52). Houve professor que apontou que sua prática avaliativa teve como base a experiência durante a formação acadêmica (alguns com influência positiva dos métodos usados por seus professores, outros, não), e/ou pela vivência tida em sala de aula. Destaca-se algumas das respostas: "Está relacionada à minha formação e experiência de sala de aula (Colaborador 6)". " [...] isso resulta das experiências que tive ao longo de minha docência. (Colaborador 10)". "Em parte, no entanto, a prática em sala de aula também contribuiu para eleger os métodos" (Colaborador 9).

O estudo das teorias de avaliação durante a formação do professor é primordial, bem como a prática avaliativa adotada pelos docentes que formam outros. Logo, o futuro educador tem, no seu professor de graduação/pós-graduação, um referencial prático de como avaliar o estudante enquanto está sendo avaliado. Uma prática de avaliação que pode ter influência positiva ou negativa ao futuro docente. Influências estas que incidem nas escolhas dos 
instrumentos e métodos de avaliação pelo docente em atuação.

Para conhecer os instrumentos avaliativos usados pelos professores no processo de aprendizagem foram propostos, os seguintes questionamentos: "No momento em que você avalia o aluno do PROEJA que aspectos você leva em consideração? (Questão 3.6); Quais instrumentos você utiliza para avaliar os alunos do PROEJA? (Questão 3.7)” (LOPES, 2011, p.53).

Verificou-se que os aspectos referentes à "aprendizagem e participação" foram os escolhidos em maior percentual pelos professores do PROEJA, respectivamente, $28 \%$ e $26 \%$, também considerado o "interesse (17\%) e assiduidade (13\%)" dos alunos. Um participante acrescentou ainda que no momento de avaliar, observa, quando possível "o desempenho do aluno no mercado de trabalho" (Colaborador 12). Essa afirmação abrange a concepção de avaliação com enfoque na aplicação prática, no cotidiano do aluno e a noção do entendimento da necessidade do ensino está voltada à realidade do estudante. (LOPES, 2011).

Cabe ressaltar que os aspectos de participação, assiduidade, interesse e até mesmo o desempenho do aluno no mercado de trabalho são subjetivos e necessitam de critérios prévios para análise. Participar significa necessariamente aprender? Como saber o que o aluno aprendeu?

Sobre os instrumentos para avaliar os alunos, os professores utilizam, em ordem de preferência, de provas escritas, atividades diárias, trabalhos em grupos e individuais; exercícios práticos e seminários e, por último, testes orais. Para eles as "atividades diárias, provas escritas e seminários" estão entre os instrumentos que melhor diagnosticam a aprendizagem do estudante.

A respeito do tipo de teste que os professores utilizam, foram apontadas as opções de: prova objetiva, subjetiva, objetiva e subjetiva, sendo que todos os professores afirmaram ter preferência pelas escritas com questões subjetivas e objetivas.

A identificação da escolha pelos docentes por esses instrumentos avaliativos, ênfase à prova escrita, poderia ser vista como comum? E em se tratando de um curso de Jovens e Adultos (que além dessa especificidade oferece uma habilitação técnica profissionalizante), como esse professor avalia o aluno nas aulas práticas? Entre as respostas a uma questão com base na dúvida sobre como era a avaliação nas aulas práticas, constam como critérios nessa avaliação, segundo descritos pelos colaboradores, a participação, observação, pontualidade, desenvoltura, atuação do aluno durante a aula, entre outros. Ainda em resposta ao questionamento, assim afirmou o Colaborador 12. "Com relatórios, prova oral, discussão de 
situações hipotéticas, diário de bordo". (LOPES, 2011, p. 56).

Conforme elucidado no parágrafo anterior, o ato de avaliar na educação de jovens e adultos em um curso que é profissionalizante, pauta-se em critérios diversos para o diagnóstico da aprendizagem do aluno também durante as aulas práticas. Assim, apresenta-se a questão central da análise da avaliação a partir dessa experiência na modalidade da educação básica profissional desta realidade em estudo. As respostas dos professores às demais questões levantadas durante a pesquisa do mestrado (inclusive as que não foram evidenciadas nesse texto) apontam, em teoria, uma perspectiva almejada de avaliação.

As concepções apresentadas pelos docentes confluem com as concepções ideais de avaliação defendidas neste trabalho. Todavia, há duas questões que incomodou a pesquisadora quando da análise da prática avaliativa do curso PROEJA, uma delas refere-se ao uso pela instituição da Semana de Prova e o fato de verificar os professores utilizando as mesmas posturas avaliativas dos cursos profissionalizantes oferecidos no turno diurno com os alunos jovens e adultos estudantes do noturno (alguns trabalhadores no contraturno). Incômodo este sendo anterior à elaboração do questionário da pesquisa e que permaneceu após os resultados dela. Tendo em vista a afirmativa da maioria dos professores (11) quanto ao fato de concordarem com a semana de prova e de recuperação existentes na escola.

Entre os requisitos para a prática avaliativa Campus Araguatins, do IFTO, conforme aponta Lopes (2011), estavam:

\footnotetext{
"O professor tem de utilizar pelo menos dois instrumentos avaliativos que atendam ao valor médio de duas avaliações, sendo um desses, obrigatoriamente, uma prova escrita. Tal exigência tem como justificativa a capacitação dos alunos para o vestibular e o mercado de trabalho;

"[...] a participação dos estudantes na semana de avaliação, semana de recuperação e de provas recuperativas bem como, em projetos que visam classificar, tal como: "O Projeto os 10 mais", que visa colocar em destaque (jornal eletrônico do Instituto juntamente com premiações) a cada bimestre os estudantes que tiraram as melhores notas no conjunto das disciplinas do período". (p. 72).
}

Mesmo tendo que seguir a tais regulamentações os professores explicitaram como entendem e almejam que seja a avaliação. Para a última pergunta do questionário: "Quanto a sua ideia sobre avaliação, gostaria de acrescentar alguma outra informação?” (LOPES, 2011, p. 83), alguns deles assim responderam:

a) “A avaliação não é o fim do processo de ensino aprendizagem, mas ela deve está inserida em todo o processo, funcionando como um mecanismo que evidencie os caminhos que devem ser percorridos como devem ser percorridos". (Colaborador 07). 
b) “Avaliar não é fácil, é uma tarefa complexa e às vezes duvidosa, estamos nos policiando todo o tempo para não rotular os alunos e nem prejudicá-los. Porém, necessária como parte do processo ensino-aprendizagem". (Colaborador 12);

c) “A avaliação não é o fim do processo de ensino aprendizagem, mas ela deve está inserida em todo o processo, funcionando como um mecanismo que evidencie os caminhos que devem ser percorridos como devem ser percorridos". (Colaborador 07);

d) “Que a avaliação não seja usada para punir". (Colaborador). (LOPES, 2011, p. 83, grifo nosso);

Pode-se observar com alguns dos resultados da pesquisa que os depoimentos dos docentes sobre avaliação do processo ensino-aprendizagem abordavam definições que ora se visualizava uma função de avaliação construtivista/mediadora, emancipatória, dialética libertadora, ora apresentava características de uso da análise tradicional. Todavia, compreendeu-se que a prática de avaliação na educação profissional de jovens e adultos, devem aproximar-se da ideia que os professores defendem. Seria, na prática, outra teoria?

\section{CONSIDERAÇÕES}

Apresentar um novo olhar sobre um trabalho desenvolvido há 10 anos, foi um desafio. Todavia, este artigo pode levar o leitor a compreender que os resultados da pesquisa (diagnosticados em um contexto diferente do atual) podem ser vistos como contemporâneos. Em suma, há décadas educadores discutem sobre a polaridade entre a avaliação classificatória e as demais concepções desta em cunho construtivista e sobre a distância entre teoria e prática.

Compreende-se que muitos professores em atuação na Educação de Jovens e Adultos têm conhecimento das teorias ideais de avaliação, seja na sua formação ou da sua prática de ensino, mas que, ao final, não conseguem recorrer a outros instrumentos de avaliação (não classificatórios) porque estão limitados às regulamentações rígidas e técnicas do seu sistema de ensino?

As dificuldades de avaliar um aluno Jovem ou Adulto, em sua maioria trabalhador, em um curso de educação profissionalizante, podem ser as mesmas ao considerar o estudante no ensino regular. Logo, as barreiras da compreensão do que é avaliar é existente não somente na escola, mas em todos os envolvidos neste processo, desde os pais ao cobrarem pelas "notas" dos filhos premiando-os por alcançarem bom conceito nas disciplinas, até o filho (ou mesmo o pai/mãe, trabalhador (a) e estudante) ao ir para escola com o objetivo de tirar notas consideráveis para a aprovação.

Essa barreira também está na sociedade quando a empresa, por exemplo, tem que $\underline{\text { escolher se recebe, ou não, um jovem e/ou adulto formado em uma instituição em um programa }}$ 
de profissionalização como o PROEJA, e para isso se atenta a verificar o conceito de tal entidade diante dos padrões de qualidade do ensino implementados no país para classificar qual (ou quem) é melhor.

Poder-se afirmar que o ensino no Brasil ainda apresenta característica do método tradicional, inclusive na modalidade de Jovens e Adultos com base na Educação Profissionalizante? O uso da prova escrita como instrumento preferencial, na modalidade de EJA, em um curso que deveria ter uma proposta de integração de currículo entre as bases comuns e técnica de uma determinada profissional seria um indicativo que ainda há distância entre a teoria e a prática de uma avaliação transformadora?

O processo de avaliação, seja na educação de jovens e adultos, como em qualquer outra, deve ser constantemente discutido. Mudanças nas posturas diante da avaliação da aprendizagem deve partir de todos, a iniciar por reflexões-base, como: estudar para tirar nota na prova e passar de ano/série? Avaliar para classificar?

\section{REFERÊNCIAS}

BRASIL, Congresso Nacional de Educação. Lei Federal no 9.394 de 20 de dezembro de 1996. Estabelece as diretrizes e bases da educação nacional. Brasília DF: D.O.U. de 22/12/1996.

Decreto no 5.478 de 24 de junho de 2005. Institui no âmbito das instituições federais de educação tecnológica, o Programa de Integração da Educação Profissional ao Ensino Médio na Modalidade de Educação de Jovens e Adultos (PROEJA). Brasília: 2005a.

$2005 b$.

Documento - base PROEJA, de 25 de janeiro de 2005. 2ª Ed. Brasília: MEC/SETEC,

Presidente da República. Lei 11. 741 de 16 de julho de 2008: Altera dispositivos da Lei 9394/96 20 de dezembro de 1996, que estabelece as diretrizes e bases da educação nacional, para redimensionar, institucionalizar e integrar as ações da educação de jovens e adultos e da educação profissional e tecnológica: O Presidente, 2008.

DARSIE, Marta Maria Pontin (org.) A avaliação no trabalho docente: concepções e práticas em Educação Matemática. Cuiabá: EdUFMT/FAPEMAT, 2010.

FRIGOTTO, Gaudêncio, CIAVATTA, Maria, \& RAMOS, Marise. A política de educação profissional no governo Lula: um percurso histórico controvertido. Educação e Sociedade, Campinas, vol. 26, nº. 92, pp.1087-1113, especial - out. 2005.

GADOTTI, Moacir \& ROMÃO, José Eustáquio. Educação de Jovens e Adultos - teoria, prática e proposta. 10 ed. São Paulo - Cortez, Instituto Paulo Freire, 2008. (Guia da escola cidadã, v.5). 
HOFFMANN, Jussara. Avaliação mediadora: uma prática em construção da pré-escola à universidade. 22 ed. Porto Alegre: Mediação, 2004.

. Avaliação mito e desafio: uma perspectiva construtivista. 35 ed. Porto Alegre: Mediação, 2005.

KUENZER, Acácia. Ensino médio e profissional: as políticas do estado neoliberal. São Paulo: Cortez, 2007.

LISITA, Verbena Moreira S. de S. \& SOUSA, Luciana Freire E. C. P. Sousa (org). Políticas educacionais, práticas escolares e alternativas de inclusão escolar. Rio de Janeiro: DP\& A, 2003.

LOPES, Kênya Maria Vieira. Avaliação do Processo Ensino/Aprendizagem no PROEJA do Instituto Federal do Tocantins Campus Araguatins. 2011. 90 f. Dissertação. (Mestrado em Educação Agrícola). Instituto de Agronomia, Universidade Federal Rural do Rio de Janeiro, Seropédica, 2011. Disponível em:

http://cursos.ufrrj.br/posgraduacao/ppgea/files/2015/08/Kenya-Maria-Vieira-Lopes.pdf.

Acesso em: 14. fev. 2019.

LUCKESI, Cipriano Carlos. Avaliação da aprendizagem escolar: estudos e proposições. 19 ed. São Paulo: Cortez, 2008.

MANFREDI, Silvia Maria. Educação Profissional no Brasil. São Paulo: Cortez, 2002.

SAUL, Ana Maria. Avaliação emancipatória: desafio à teoria e à prática de avaliação e reformulação de currículo. São Paulo: Autores Associados, 1998.

SOUSA, Clarilza Prado de. (org). Avaliação do rendimento escolar. 13 ${ }^{\text {a }}$ Ed. Campinas: Papirus, 2005.

VASCONCELLOS, Celso dos Santos. Avaliação: concepção dialética-libertadora do processo de avaliação escolar. $16^{\text {a }}$ ed. São Paulo: Libertad 2006.

\section{APÊNDICE 1}

\section{AGRADECIMENTOS}

Aos professores colaboradores da pesquisa. Ao IFTO, ao PPGECEM/REAMEC e UFMT.

\section{FINANCIAMENTO}

"Não houve financiamento."

\section{CONTRIBUIÇÕES DE AUTORIA}

Resumo/Abstract/Resumen: Pedro Caetano Silva Grego

Introdução: Kênya Maria Vieira Lopes e Nádia Maria Pereira de Souza

Referencial teórico: Kênya Maria Vieira Lopes e Nádia Maria Pereira de Souza

Análise de dados: Kênya Maria Vieira Lopes e Nádia Maria Pereira de Souza

Discussão dos resultados: Kênya Maria Vieira Lopes e Nádia Maria Pereira de Souza

Conclusão e considerações finais: Kênya Maria Vieira Lopes e Nádia Maria Pereira de Souza

Referências: Kênya Maria Vieira Lopes e Nádia Maria Pereira de Souza 
Revisão do manuscrito Kênya Maria Vieira Lopes e Nádia Maria Pereira de Souza

Aprovação da versão final publicada: Kênya Maria Vieira Lopes e Nádia Maria Pereira de Souza

\title{
CONFLITOS DE INTERESSE
}

Os autores declararam não haver nenhum conflito de interesse de ordem pessoal, comercial, acadêmico, político e financeiro referente a este manuscrito.

\section{DISPONIBILIDADE DE DADOS DE PESQUISA}

Os dados que suportam os resultados deste estudo poderão ser disponibilizados mediante solicitação plausível, cabendo aos autores determinar a plausibilidade da solicitação, bem como as condições (licença) de acesso e uso.

\section{CONSENTIMENTO DE USO DE IMAGEM}

\author{
"Não se aplica."
}

\section{COMO CITAR - ABNT}

LOPES, Kênya Maria Vieira; SOUZA, Nádia Maria Pereira de. A avaliação na Educação Profissional de Jovens e Adultos. REAMEC - Rede Amazônica de Educação em Ciências e Matemática. Cuiabá, v. 9, n. 2, e21061, maio a agosto, 2021. https://doi.org/10.26571/reamec.v9i2.12788

\section{COMO CITAR - APA}

Lopes, K. M. V., \& Souza, N. M. P. (2021). A avaliação na Educação Profissional de Jovens e Adultos. REAMEC - Rede Amazônica de Educação em Ciências e Matemática, 9(2), e21061. https://doi.org/10.26571/reamec.v9i2.12788

\section{LICENÇA DE USO}

Licenciado sob a Licença Creative Commons Attribution-NonCommercial 4.0 International (CC BY-NC 4.0). Esta licença permite compartilhar, copiar, redistribuir o manuscrito em qualquer meio ou formato. Além disso, permite adaptar, remixar, transformar e construir sobre o material, desde que seja atribuído o devido crédito de autoria e publicação inicial neste periódico.

\section{DIREITOS AUTORAIS}

Os direitos autorais são mantidos pelos autores, os quais concedem à Revista REAMEC - Rede Amazônica de Educação em Ciências e Matemática - os direitos exclusivos de primeira publicação. Os autores não serão remunerados pela publicação de trabalhos neste periódico. Os autores têm autorização para assumir contratos adicionais separadamente, para distribuição não exclusiva da versão do trabalho publicada neste periódico (ex.: publicar em repositório institucional, em site pessoal, publicar uma tradução, ou como capítulo de livro), com reconhecimento de autoria e publicação inicial neste periódico. Os editores da Revista têm o direito de proceder a ajustes textuais e de adequação às normas da publicação.

Obs.: Deixar este texto completo.

\section{PUBLISHER}

Universidade Federal de Mato Grosso. Programa de Pós-graduação em Educação em Ciências e Matemática (PPGECEM) da Rede Amazônica de Educação em Ciências e Matemática (REAMEC). Publicação no Portal de Periódicos UFMT. As ideias expressadas neste artigo são de responsabilidade de seus autores, não representando, necessariamente, a opinião dos editores ou da referida universidade.

Obs.: Deixar este texto completo.

\section{EDITOR}

Dailson Evangelista Costa 10

\section{HISTÓRICO}

Submetido: 20 de julho de 2021 .

Aprovado: 03 de agosto de 2021.

Publicado: 28 de agosto de 2021. 